\title{
Mensurações do eu: apontamentos sobre os impactos da datificação nas representações da subjetividade no contexto profissional
}

\author{
Rebeka Figueiredo da Guarda \\ Universidade de São Paulo, Escola de Comunicações e Artes, São Paulo, SP, Brasil \\ rebeka.figueiredo@usp.br
}

DOI: https://doi.org/10.26512/rici.v13.n1.2020.29528

Recebido/Recibido/Received: 2020-01-02

Aceitado/Aceptado/Accepted: 2020-02-10

Resumo:Este trabalho tem como objetivo discutir os processos de representação das subjetividades no ambiente digital e suas possíveis implicações no mundo do trabalho a partir da observação de softwares que oferecem seleção automatizada de profissionais. Com base na semiótica peirceana, realizamos um debate teórico sobre a produção e circulação de significados no ambiente digital, problematizando os possíveis vieses presentes nos dados e na análise de candidatos a vagas de emprego feita por meio de algoritmos. Por fim, pontuamos os limites da representação das subjetividades e destacamos a importância da observação de questões éticas nos processos de codificação e filtragem de informações no meio digital.

Palavras-chave: representação. subjetividade. análise preditiva. banco de dados. algoritmo.

Measurements of the Self: Notes on the impacts of datafication on the representations of subjectivity within the professional context

Abstract: This paper aims to discuss the processes of representation of subjectivities in the digital environment and their possible implications in the world of work from the observation of software that offer automated selection of professionals. Based on Peircean semiotics, we conduct a theoretical debate on the production and circulation of meanings in the digital environment, problematizing the possible biases present in the data and the analysis of job vacancy candidates through algorithms. Finally, we point out the limits of the representation of subjectivities and highlight the importance of observing ethical issues in the processes of coding and filtering information in the digital environment. Keywords: representation. subjectivity. predictive analysis. database. algorithm.

\section{Mediciones del Yo: Apuntes sobre los impactos de la dataficación en las representaciones de la subjetividad dentro del contexto profesional}

Resumen: Este artículo tiene como objetivo discutir los procesos de representación de las subjetividades en el entorno digital y sus posibles implicaciones en el mundo del trabajo a partir de la observación de softwares que ofrecen una selección automatizada de profesionales. Basados en la semiótica de Peirce, hicimos un debate teórico sobre la producción y circulación de significados en el entorno digital, problematizando sobre los posibles sesgos en los datos y en el análisis de candidatos para puestos de trabajo realizado a través de algoritmos. Finalmente, señalamos los límites de la representación de las subjetividades y destacamos la importancia de observar los problemas éticos en los procesos de codificación así como en el filtrado de información dentro del entorno digital.

Palabras clave: representación. subjetividad. análisis predictivo. banco de datos. algoritmo. 


\section{Introdução}

A proposta desta comunicação é discutir os processos de representação das subjetividades no ambiente digital e suas possíveis implicações no mundo do trabalho. Nos últimos anos, a organização de grandes bancos de dados digitalizados e o uso de inteligência artificial e aprendizado de máquina (machine learning) permitiram a automação de diferentes tarefas, entre elas a escolha de profissionais em processos seletivos de emprego. Isso significa que a leitura de currículos por pessoa natural e a entrevista pessoal, entre outras etapas do recrutamento, poderiam ser substituídas por análises automatizadas de perfis digitais. Em resumo, sai a pessoa e entram os dados que a representam. Os dados indicarão se o sujeito é apto ou não a uma vaga. Essa é a promessa, por exemplo, do software brasileiro de recrutamento Kenoby e da ferramenta de recrutamento Linkedln Recruiter, da rede social Linkedln. ${ }^{1}$

Entretanto, seria possível mensurar um ser humano a partir de seus dados pessoais? De que forma esses dados são coletados e preparados para posterior avaliação? A análise de dados é suficiente para medir a aptidão de uma pessoa para uma determinada função? Que significados podem ser atribuídos aos profissionais a partir dos dados relacionados a eles? A partir destas perguntas, este trabalho tem os seguintes objetivos: (1) debater os processos de representação e de produção e circulação de sentidos no ambiente digital; (2) discutir os possíveis vieses presentes nos dados e na seleção automatizada de profissionais; e (3) apontar as possíveis consequências, para os sujeitos e para a sociedade, dos processos de digitalização e mensuração das subjetividades.

Para isso, escolhemos a Semiótica desenvolvida pelo filósofo e lógico norte-americano Charles S. Peirce (2000) como base teórico-metodológica, pois esta é uma teoria geral e formal sobre as formas como representamos e significamos a realidade. Ao longo desta comunicação, a teoria semiótica é relacionada à discussões sobre: (1) as mudanças trazidas pelo banco de dados como novo gênero da cultura (MANOVICH, 2001; MANOVICH, 2015); (2) a datificação da experiência e a crença na neutralidade dos dados e dos algoritmos (O'NEIL, 2016; VAN DIJCK, 2017); (3) os agenciamentos promovidos por plataformas e algoritmos na internet e suas influências nos processos de significação (GILLESPIE, 2014; PARISER, 2012); (4) a emergência da chamada "cultura proxy" (FLORIDI, 2014; FLORIDI, 2015); e (5) os riscos da tentativa de mensurar e operacionalizar a subjetividade humana em prol do atual sistema econômico (COULDRY \& MEJIAS, 2019).

\footnotetext{
1 Para mais informações sobre as duas ferramentas citadas, ver: <http://www.kenoby.com/> e
} <https://business.linkedin.com/pt-br/talent-solutions/recruiter>. Acesso em: 10 dez 2019. 
Nesse sentido, realizamos, a partir da observação do software Kenoby e da ferramenta Linkedln Recruiter, uma análise semiótica dos processos de recrutamento automatizado, buscando ampliar as possibilidades de compreensão do objeto e apontar as variáveis que podem incidir sobre a escolha de um profissional por meio de dados digitalizados. Nossa proposta é promover um debate teórico e filosófico sobre as questões delimitadas acima. Por conseguinte, este trabalho não discute o funcionamento de algoritmos e/ou de outras lógicas computacionais do ponto de vista técnico.

Entre os resultados, observamos que o processo de recrutamento automatizado promove uma mensuração das subjetividades que atende principalmente aos anseios de otimização e eficiência de empresas, ou seja, a mensuração do eu permite que os sujeitos sejam enquadrados às lógicas do atual sistema econômico. Nesse sentido, destaca-se a importância do questionamento sobre como as informações relacionadas aos sujeitos são coletadas, transformadas em dados e analisadas para que a diversidade e as características particulares dos profissionais sejam valorizadas. Caso contrário, o processo de seleção automatizada pode levar à homogeneização e à ampliação das desigualdades.

\section{Metodologia}

Compreendemos que a escolha dos métodos e técnicas de investigação está orientada, desde o princípio, pela linha teórica, conforme defende Maria Immacolata Vassallo de Lopes: “o objeto de estudo já é desde o início uma construção teórica, e a opção pelos métodos é imposta antes pela teoria que pelos fatos da realidade" (2001, p. 104). A autora sugere que as decisões teóricas e metodológicas estejam interligadas em todos os níveis da pesquisa, em uma dialética que permita o aprofundamento da investigação e a compreensão de seus limites.

Assim, destacamos que a abordagem dos processos de seleção automatizada de profissionais é feita aqui a partir do ponto de vista da semiótica desenvolvida por Charles $\mathrm{S}$. Peirce (2000), pois entendemos que esta teoria geral fornece as bases para a compreensão dos múltiplos fatores relacionados aos processos de representação e significação. Nossa proposta consiste, sobretudo, no mapeamento do objeto, qual seja, a seleção automatizada de profissionais, com vistas a ampliar a compreensão sobre o mesmo. Segundo lasbeck (2017, p. 203), a perspectiva semiótica pressupõe a exploração do objeto de modo que se evidenciem suas distintas possibilidades de sentido, sem a pretensão de esgotá-lo ou obter conclusões definitivas:

Trabalhar semioticamente um objeto de pesquisa significa relacioná-lo com o maior e o mais significativo número e natureza de possibilidades que ele 
comporta, buscando compreendê-lo em movimento, dinâmico e operante, ainda que tais relações possam, eventualmente, estabelecer paradoxos incontornáveis.(IASBECK 2017, p. 203)

Assim, o software Kenoby e a ferramenta Linkedln Recruiter servem de inspiração para a discussão teórica sobre os possíveis fatores relacionados ao processo de recrutamento automatizado de profissionais. Deste modo, o trabalho consistiu na contemplação e delimitação do fenômeno a partir da observação dos sites do Kenoby e do LinkedIn Recruiter. Em seguida, buscamos situá-lo no atual contexto e discuti-lo sob a perspectiva semiótica, relacionando a literatura pertinente aos problemas identificados e tecendo nossas considerações. Informamos que não realizamos testes em nenhuma das plataformas citadas, de modo que nossa análise está baseada nos discursos encontrados nos sites dessas plataformas e na confrontação deles com a literatura.

\section{Revisão da literatura}

Para discutir o funcionamento da seleção automatizada do ponto de vista das formas como os sujeitos são representados e mensurados a partir de dados, apresentamos, inicialmente, um resumo da teoria semiótica. Nela, os processos de representação e significação estão relacionados à noção de signo. É necessário pontuar que a semiótica peirceana faz parte de uma arquitetura filosófica mais ampla que começou a ser desenvolvida por Charles S. Peirce a partir da fenomenologia, em meados de 1860. No início, o objetivo do autor era investigar como surgem as nossas concepções a respeito da realidade, pois ele estava interessado em desvendar as origens do conhecimento. Peirce procurou examinar todos os fenômenos que se apresentam à mente e chegou a três categorias formais e universais que estariam presentes em todos eles. Posteriormente denominadas primeiridade, secundidade e terceiridade, as categorias são dinâmicas e interdependentes, podendo ser encontradas em qualquer tipo de fenômeno, tais como um ruído, uma palavra, uma conversa, um filme, etc. (SANTAELLA, 2014). É na terceiridade que se encontra a noção de signo.

De modo simplificado, um signo (ou representamen) pode ser definido como qualquer coisa de qualquer espécie, que representa ou indica outro algo ou alguém, o objeto do signo, e que produz um efeito, o interpretante do signo (PEIRCE, 2000). A partir de sua ontologia tripartite, Peirce chegou a dez classes de signos. A tríade mais conhecida é aquela que define o signo em conexão com o objeto, classificando-o como: ícone, quando o signo representa o objeto por uma relação de semelhança ou qualidade; índice, quando o signo possui uma relação material com seu objeto; e símbolo, quando o signo é uma lei, um conceito, uma regra, sem nenhuma conexão material com o objeto (PEIRCE, 2000, p. 52). Dessa forma, o perfume 
de uma flor pode funcionar como um signo indicial que representa uma flor para um possível intérprete. Já o desenho de uma flor poderia ser classificado como um signo icônico e a palavra "flor" seria um signo simbólico.

Os signos têm distintas naturezas e se relacionam de maneira contínua. Por serem baseados em leis, os símbolos só podem ser compreendidos a partir do código cultural em que estão inseridos. Entretanto, eles estão fundamentados no mundo físico, isto é, eles se desenvolvem à medida em que são confrontados com a realidade. A generalidade permite que os símbolos sejam capazes de comunicar informações, produzindo interpretantes em uma comunidade que os compartilham. Destacamos que o signo nunca substitui o objeto em sua totalidade, mas "pressupõe uma familiaridade com algo a fim de veicular alguma informação ulterior sobre esse algo" (PEIRCE, 2000, p. 47). Por conseguinte, os signos são mediadores que permitem que a comunicação se estabeleça entre duas ou mais pessoas.

De acordo com Peirce (2000, p. 61), representar é "estar em lugar de, isto é, estar numa relação com um outro que, para certos propósitos, é considerado por alguma mente como se fosse esse outro." Assim, os dados armazenados em uma plataforma de recrutamento podem cumprir a função de representar uma determinada pessoa para outra pessoa ou para uma organização. Argumentamos, uma vez mais, que a geração e a circulação de significados só podem emergir de relações triádicas indecomponíveis entre signo, objeto e interpretante, em que signos remetem a outros signos mais desenvolvidos, em um processo dinâmico e sem final definido.

E como ficam as representações da subjetividade em meio a um universo composto por signos? Para discuti-las, é necessário abordar a subjetividade sob a perspectiva semiótica. Para Peirce (2000, p. 306), o homem é um signo, mais especificamente um símbolo. Nesse sentido, o homem é processo, resultado e agente da prática sígnica (COLAPIETRO, 2014). O eu é um signo que emerge das relações e das experiências:

\footnotetext{
Uma criança ouve dizer que o fogão está quente. Mas não está, ela diz; e de fato aquele corpo central não está tocando o fogão, e frio ou quente só está aquilo que esse corpo toca. Mas ela toca o fogão, e descobre que aquele testemunho se confirma de um modo notável. Assim, ela se torna consciente da ignorância, e é necessário supor um eu ao qual essa ignorância pode ser inerente. (PEIRCE, 2000, p. 249).
}

Entretanto, o eu não pode ser reduzido à materialidade, pois ele possui hábitos, sentimentos e pensamentos, além de sua identidade existencial, o corpo:

Quando eu, isto é, meus pensamentos, entro em outro homem, não levo comigo necessariamente todo meu ser, mas o que levo de fato é a semente da parte que não estou levando - e se carrego a semente de toda minha essência, carrego a de todo meu ser concreto e potencial. (PEIRCE, 2000, p. 310). 
A partir de signos que são corporificados na mente, o homem é capaz de ultrapassar a materialidade do corpo e levar adiante o que está em seu interior. Peirce (1892) evidencia que o eu não é uma instância imutável e estática ao afirmar que a personalidade só pode existir em referência ao futuro, não podendo ser captada em um instante. Em outras palavras, é impossível compreender a personalidade em sua totalidade a partir de um ponto específico:

Essa referência ao futuro é um elemento essencial da personalidade. Se os fins de uma pessoa já fossem explícitos, não haveria espaço para desenvolvimento, crescimento e vida; e consequentemente não haveria personalidade. A mera realização de propósitos predeterminados é mecânica. (PEIRCE, 1892, p. 556, tradução nossa)

Como um signo, o eu está em constante desenvolvimento e só cumprirá todas as suas potencialidades em um futuro condicional. Logo, as representações da subjetividade devem ser avaliadas como circunstanciais e incapazes de substituir o sujeito.

Na medida em que a seleção automatizada é feita a partir de dados que representam os candidatos, é preciso discutir que tipo de tratamento esses dados recebem, pois eles vão ajudar a gerar os significados que serão atribuídos aos profissionais e que determinarão se o candidato é apto ou não a uma vaga. Nesse sentido, pontuamos que as informações sobre um profissional só podem ser analisadas por uma plataforma de recrutamento após passarem por uma codificação a partir da linguagem computacional. Longe de ser um processo neutro e objetivo, essa codificação envolve escolhas capazes de incutir determinados significados aos dados.

Manovich (2001, p. 27-28) esclarece que os ambientes digitais, denominados por ele como "novas mídias", são formados por objetos compostos por códigos digitais, ou seja, representações numéricas descritas matematicamente por meio do código binário e passíveis de programação. A digitalização é feita a partir da quantificação e da classificação dos dados, que passam a fazer parte de grandes bancos e podem posteriormente ser recombinados de inúmeras formas, em distintos contextos e momentos, a partir de programações feitas por algoritmos. Para o autor, o banco de dados é um novo gênero da cultura, na medida em que, diferentemente das narrativas, as coleções de dados não têm sequência linear e podem ser acessadas, cruzadas e correlacionadas de várias formas. Segundo Manovich, "juntos, as estruturas de dados e os algoritmos são duas metades da ontologia do mundo, no ponto de vista de um computador" $(2015$, p. 11).

Gillespie explica que os algoritmos podem ser definidos, em sentido amplo, como "procedimentos codificados para transformar inputs de dados em outputs desejáveis, com base em cálculos específicos" (2014, p. 167, tradução nossa). O fato de que os algoritmos são programados para gerar resultados esperados implica que eles obedecem a certos propósitos 
de seus detentores. Por conseguinte, o autor pondera que o uso de algoritmos na seleção de informações que supostamente devem ser consideradas mais relevantes para as pessoas requer a observação das decisões humanas e institucionais que estão por trás deles.

Para investigar a influência dos algoritmos, Gillespie (2014) propõe um mapa conceitual de seis dimensões dos algoritmos que poderiam interferir e modificar os sentidos das informações que são filtradas por eles. São elas:

1.Padrões de inclusão: as escolhas por trás do que gera um índice, em primeiro lugar, o que é excluído, e como os dados são preparados para o algoritmo.

2. Ciclos de antecipação: as implicações das tentativas dos provedores de algoritmos de conhecer e prever completamente seus usuários, e como as conclusões às quais eles chegam podem importar.

3. A avaliação de relevância: os critérios pelos quais os algoritmos determinam o que é relevante, como esses critérios são ocultados de nós e como eles decretam escolhas políticas sobre conhecimento apropriado e legítimo.

4. A promessa de objetividade algorítmica: a maneira como o caráter técnico do algoritmo é posicionado como uma garantia de imparcialidade, e como essa reivindicação é mantida diante de controvérsias.

5. Entrelaçamento com a prática: como os usuários reformulam suas práticas para se adequarem a algoritmos dos quais eles dependem e como eles podem transformar algoritmos em terrenos para a disputa política, às vezes até para interrogar a política do próprio algoritmo.

6. A produção de públicos calculados: como a apresentação algorítmica dos públicos é devolvida a eles mesmos e molda a percepção de si desses públicos, e quem está melhor posicionado para se beneficiar desse conhecimento. (GILLESPIE, 2014, p. 168, grifo do autor, tradução nossa).

Essas dimensões evidenciam que os dados tratados recebem determinada valoração de acordo com a programação dos algoritmos. Ao mesmo tempo, as dinâmicas das redes e as ações dos usuários também podem contribuir para a geração de novos sentidos.

Cathy O'Neil (2016) também chama a atenção para os vieses contidos nos algoritmos ao destacar que "modelos são opiniões embutidas em matemática" (O’NEILL, 2016, p. 21, tradução nossa). Segundo ela, a promessa de objetividade e imparcialidade dos algoritmos esconde o fato de que eles são criados por pessoas e, nesse sentido, muitos carregam em suas codificações os preconceitos, mal-entendidos e vieses de seus criadores. A autora destaca que esses modelos são simplificações e que "nenhum modelo pode incluir toda a complexidade do mundo real ou as nuances da comunicação humana" (Idem, 2016, p. 20, tradução nossa).

Para Jose Van Dijck (2017), a datificação transformou-se em um novo paradigma aceito pela comunidade científica, pelos governos e pelas empresas para compreender a sociabilidade. A autora pontua que a codificação dos mais distintos aspectos da vida cotidiana - tais como amizades, relações de compras, buscas por informações, etc. - vem acompanhada de uma ideologia que prega a neutralidade e a objetividade dos dados gerados, como se eles 
pudessem expressar uma verdade absoluta sobre os comportamentos humanos. Van Dijck chama essa ideologia de dataísmo:

O dataísmo prospera partindo do pressuposto que a coleta dos dados acontece fora de qualquer estrutura predefinida - como se o Twitter facilitasse a atividade de microblog apenas para gerar dados vivos - e as análises de dados acontecessem sem um objetivo prévio, como se os analistas de dados analisassem aqueles dados apenas pelo interesse na acumulação de conhecimento sobre o comportamento humano. (VAN DIJCK, 2017, p. 48).

A compreensão dos interesses e motivações por trás da análise de dados permitiria, assim, que os processos que envolvem seleção automatizada sejam considerados a partir de suas limitações. Entretanto, o que observamos hoje é a normalização dos processos de análise preditiva a partir de dados sem que haja uma discussão sobre os riscos e vieses envolvidos, seja por parte de empresas ou governos.

Eli Pariser (2012) aponta que o uso de algoritmos por parte de grandes corporações como Google, Facebook, Amazon e Microsoft para filtrar e classificar os dados que transitam em suas plataformas tem levado ao que o autor chama de "bolha dos filtros". Ou seja, os algoritmos fazem uma avaliação prévia das supostas preferências dos indivíduos a partir de dados pessoais e rastros de navegação e, com base nisso, permitem que os usuários tenham acesso principalmente a informações alinhadas às supostas preferências deles. Essa personalização dos conteúdos tende a determinar as informações que os usuários receberão sem que estes tenham conhecimento desses mecanismos. A partir dessa explanação, podemos questionar, no âmbito de nosso objeto de pesquisa, se os critérios usados na seleção automatizada de candidatos a vagas de emprego são claros e acessíveis aos profissionais. 0 que seria um "bom profissional" para os sistemas de recrutamento baseados em análises de dados?

A seleção automatizada de profissionais também precisa ser discutida do ponto de vista das mudanças trazidas pela digitalização da experiência. À medida em que passamos mais tempo conectados ao ambiente digital, a experiência sensível dá lugar ao que Floridi (2014) chama de "tipificação", processo em que os sujeitos passam a ser classificados e a se identificar como tipos, com base em padrões limitados à natureza do digital. Assim, "podemos conceber um ao outro como conjuntos de tipos, de gênero à religião, de papel familiar à posição de trabalho, de educação à classe social" (Ibid., p. 58, tradução nossa). Essa tendência daria lugar ao desenvolvimento do que o autor denomina "cultura proxy", em que as representações dos sujeitos no ambiente digital não apenas os representariam, mas os substituiriam completamente: 
[...] uma "cultura proxy" pode se tornar uma cultura substituta, em que proxies tornam-se meros substitutos que não apenas escondem suas referências originais [...], mas tornam difícil ou mesmo impossível alcançá-las, porque as substituem totalmente, sem qualquer ligação residual a uma realidade alternativa." (FLORIDI, 2015, p. 490, tradução nossa).

Retomando o conceito de signo desenvolvido por Peirce, lembramos que o signo representa apenas um fragmento do objeto. Além disso, um signo está sempre em desenvolvimento. Nesse sentido, se os dados substituírem os sujeitos completamente em vez de apenas representá-los em um contexto específico, corremos o risco de que o processo de datificação se descole da realidade e do que nos torna humanos, servindo apenas aos interesses de otimização e eficiência do sistema econômico.

A transformação das relações sociais em dados que posteriormente geram lucros a grandes companhias são características do chamado "colonialismo de dados", segundo Couldry e Mejias (2019): "as plataformas digitais são os meios tecnológicos que produzem um novo tipo de 'social' para o capital: ou seja, o social de uma forma que pode ser continuamente rastreado, capturado, classificado e contado como valor 'dados'" (COULDRY; MEJIAS, 2019, p. 341, tradução nossa). O uso de ferramentas tecnológicas para a produção do social para o mercado tem como consequência o que os autores denominam "colonização do self', uma vez que essas tecnologias teriam a capacidade de se interpor à relação do eu consigo mesmo. Isto posto, pode-se afirmar que o eu teria sua autonomia e potencialidades reduzidas à medida em que a experiência humana é transformada em dados, enquadrada a padrões e manipulada a partir de modelos preditivos.

\section{Resultados}

De modo geral, a análise sobre a seleção automatizada de profissionais aponta para um processo em que as particularidades dos sujeitos podem ser suplantadas durante as generalizações que transformam características subjetivas em dados que se pretendem objetivos. Descrevemos a seguir nossos resultados, relacionando-os à literatura exposta no item anterior.

O Kenoby é apresentado como um software de recrutamento e seleção. A empresa foi fundada em 2015 no Brasil e é residente do Cubo Itaú, um centro de empreendedorismo mantido pelo Banco Itaú. ${ }^{2}$ A proposta do software é realizar o recrutamento automatizado de profissionais, ou seja, selecionar os melhores candidatos para uma determinada vaga a partir dos dados relacionados a eles e das exigências da empresa que está buscando um profissional.

\footnotetext{
${ }^{2}$ Fonte: <http://www.kenoby.com/sobre/>. Acesso em: 10 dez 2019.
} 
O processo é feito a partir de um conjunto de dados armazenado no sistema, que são selecionados e analisados a partir de algoritmos e cujo resultado é apresentado em uma interface acessível ao usuário responsável por gerir a seleção.

Em seu discurso, o Kenoby traz a promessa de objetividade, como pode ser observado em um dos textos do blog da empresa: "para o $\mathrm{RH}$, ser orientado a dados implica em ter a objetividade de ter uma base de informações para auxiliar nas decisões corporativas" (KENOBY, 2018). O software possibilita o uso de testes e filtros para a seleção de candidatos. Além de ter uma base de dados própria, o Kenoby também integra bases de dados de outros sites de vagas, o que leva à centralização da seleção de profissionais: "analise 20 candidatos e não 200: use o filtro avançado do Kenoby para triar os candidatos vindos das diferentes fontes" (KENOBY, 2019).

Outrossim, o Kenoby também indica que a mensuração dos sujeitos é feita por meio de avaliações que permanecem disponíveis na plataforma mesmo após a finalização de um processo seletivo: "deixe registrados todos os pareceres de entrevistas, notas e qualificações [...]. Com o Kenoby, seus candidatos ficarão sempre disponíveis para futuras contratações" (KENOBY, 2019). Nesse sentido, a partir da situação hipotética de que um profissional tenha sido mal avaliado em um processo seletivo, cabe perguntar se ele já seria automaticamente excluído em seleções futuras, ou se teria a chance de concorrer novamente.

Uma vez que os dados são moldados e armazenados em bancos de dados, eles ficam disponíveis para a análise das empresas contratantes desses serviços em diferentes momentos. Isso indica possíveis prejuízos aos candidatos, uma vez que eles poderão ser analisados no futuro com dados coletados no passado, sem que se considerem as mudanças pelas quais os sujeitos passaram após a coleta de tais informações.

A segunda plataforma escolhida para a observação de nosso problema é o Linkedln Recruiter, uma ferramenta de recrutamento e seleção do Linkedln, rede social lançada em 2003 e que hoje conta com mais de 660 milhões de usuários em 200 países e regiões. ${ }^{3}$ O Brasil é a quarta nação com o maior número de inscritos, 40 milhões, atrás apenas dos Estados Unidos, da Índia e da China. A rede foi comprada pela Microsoft em 2016. Assim como o Kenoby, a ferramenta promete a seleção automatizada de profissionais. Neste caso, o processo é feito com base nos usuários cadastrados na rede social Linkedln e na integração de bancos de dados de outros softwares de seleção. É interessante observar que, em vez de estimular a diversidade de profissionais selecionados, a rede sugere que seus filtros sejam usados para encontrar mais profissionais com características semelhantes: "o candidato ideal

\footnotetext{
${ }^{3}$ Fonte: <https://news.linkedin.com/news>. Acesso em: 10 dez 2019.
} 
pode ser difícil de definir. Basta inserir o nome de uma pessoa de destaque e nós localizaremos mais pessoas semelhantes a ela." (LINKEDIN RECRUITER, 2019).

No caso do Linkedln Recruiter, cabe ressaltar o conflito de interesses em sua proposta, uma vez que a rede social Linkedln serve aos interesses de candidatos em busca de recolocação profissional e, ao mesmo tempo, aos interesses de recrutadores e empresas. Em sua política de privacidade, a rede informa aos usuários que coleta dados pessoais que são posteriormente usados em seus serviços:

Usamos os dados que temos sobre você (ex.: dados que você fornece, que coletamos sobre sua interação com nossos Serviços e por inferências que fazemos[...]) para recomendar conteúdo e conversas relevantes em nossos Serviços, sugerir competências que talvez você deseje adicionar ao seu perfil e competências de que você pode precisar [...]. (LINKEDIN, 2019).

O LinkedIn Recruiter também oferece a possibilidade de selecionar candidatos por meio de palavras-chave e filtros, tais como cargo, localização, habilidades, educação/formação acadêmica, companhias em que o candidato já atuou etc. À luz do debate teórico realizado na seção anterior, pontuamos que a seleção feita a partir de tipos - como cargo ou formação acadêmica - pode gerar a exclusão precoce de muitos profissionais, uma vez que só passarão para a próxima etapa aqueles que forem identificados com os tipos condizentes com a exigência do processo seletivo.

\section{Conclusões}

Em primeiro lugar, pontuamos que este trabalho teve como objetivo problematizar algumas questões relacionadas à datificação e às representações da subjetividade no contexto profissional. Ponderamos que o intuito não foi promover um discurso contrário à digitalização ou às análises preditivas, mas ponderar seus limites e possibilidades a partir da perspectiva semiótica. Em um contexto em que os avanços tecnológicos ocorrem de forma cada vez mais rápida e irreversível, há que se perguntar que tipos de futuros desejamos construir.

Em consonância com Gillespie (2014), O’Neil (2016), Pariser (2012) e Van Dijck (2017), destacamos que os dados e os algoritmos não são neutros. Assim, embora as plataformas de recrutamento automatizado indiquem que é possível fazer seleções de profissionais de modo mais eficiente e objetivo, o fato é que essas avaliações são feitas a partir de informações codificadas segundo padrões que já carregam alguns vieses.

É certo que não se pode cair na ingenuidade de afirmar que os processos seletivos manuais não tinham preconceitos ou outros problemas. A questão que levantamos aqui é que, no caso da seleção automatizada, é possível escalar resultados. Nesse sentido, uma vez que os vieses ocultos na codificação de dados e algoritmos podem ser multiplicados de maneira 
exponencial com a ajuda das novas tecnologias, corre-se o risco de uma ampliação das injustiças e das desigualdades caso não sejam observados os limites desse tipo de análise.

A semiótica peirceana mostra que os signos atuam como mediadores, mas não podem substituir os objetos aos quais eles se referem. Assim, os dados que representam os profissionais em plataformas de seleção nunca serão capazes de abarcar todas as nuances e particularidades desses seres humanos. Nesse sentido, qualquer processo que exclua completamente o humano carrega em seu cerne o risco de produzir resultados descolados da realidade.

E como evitar que os vieses contidos nos dados e nos algoritmos interfiram no modo como os profissionais são avaliados? Aqui não há resposta simples. Entretanto, entendemos que, se os padrões de análise são criados por pessoas e empresas, talvez o primeiro passo seja uma reflexão sobre as equipes e instituições por trás desses códigos, tanto em relação ao seu preparo ético, quanto à diversidade e à representatividade da população. Quais são os propósitos da análise preditiva e em que valores ela se baseia?

Infelizmente, não podemos responder a todas as perguntas levantadas nesta comunicação, mas elas servem de reflexão sobre os modos como a datificação da experiência e a automação podem interferir nas dinâmicas sociais. Assim, as discussões propostas neste trabalho não têm a pretensão de oferecer soluções práticas, mas apontar os desafios e os cuidados necessários para que a digitalização de informações seja acompanhada de princípios éticos capazes de assegurar a igualdade de condições para todos os seres humanos, seja em processos seletivos ou em outras situações do cotidiano.

\section{Referências}

COLAPIETRO, V. Peirce e a Abordagem do Self: uma perspectiva semiótica sobre a subjetividade humana. São Paulo: Intermeios, 2014.

COULDRY, N.; MEJIAS, U.A. Data Colonialism: Rethinking Big Data's Relation to the Contemporary Subject. Television \& New Media, v. 20, n. 4, p. 336-349, 2019. Disponível em: $<$ https://doi.org/10.1177/1527476418796632>. Acesso em: 20 jul 2019.

FLORIDI, L. A Proxy Culture. Philosophy \& Technology. Holanda, v. 28, p. 487-490, 2015. Disponível em: <https://doi.org/10.1007/s13347-015-0209-8>. Acesso em: 10 fev. 2019.

FLORIDI, L. The Fourth Revolution: How the Infosphere is Reshaping Human Reality. Oxford: Oxford University Press, 2014.

GILLESPIE, T. The relevance of algorithms. In: GILLESPIE, T.; BOCZKOWSKI, P. J.; e FOOT, K.A. (Org.). Media Technologies: Essays on Communication, Materiality, and Society. Cambridge: MIT Press, 2014. 
KENOBY.Produto. [on-line], 2019. Disponível em: <http://www.kenoby.com/produto/>. Acesso em: 10 dez 2019.

KENOBY. People Analytics: descubra como o 3 Kenoby Talks debaterá o tema! [on-line], 2018. Disponível em: <http://www.kenoby.com/blog/people-analytics-3o-kenoby-talks>. Acesso em: 10 dez 2019.

LINKEDIN. About us. LinkedIn, [on-line], 2018.Disponível em: <https://news.linkedin.com/about-us\#statistics>. Acesso em: 01 jul. 2018.

LINKEDIN RECRUITER. (2019). Tour de lançamento do produto. Disponível em: <https://business.linkedin.com/pt-br/talent-solutions/recruiter>. Acesso em: 10 dez. 2019.

MANOVICH, L. The Language of New Media. Cambridge: MIT Press, 2001.

MANOVICH, L. O Banco de Dados. In: The Language of New Media. Trad.: Camila Vieira. Revista Eco Pós, UFRJ, v. 18, n. 1. Jan. 2015. Disponível em:<https://revistas.ufrj.br/index.php/eco_pos/article/view/2366>. Acesso em: 12 out. 2018.

O'NEIL, C. Weapons of math destruction: how big data increases inequality and threatens democracy. New York: Crown Publishers, 2016.

PARISER, E. O filtro invisível: O que a internet está escondendo de você. Rio de Janeiro: Zahar, 2012.

PEIRCE, C. S. Semiótica. São Paulo: Perspectiva, 2000.

PEIRCE, C. S. The Law of Mind. The Monist, v. 2, n. 4, p. 533-559, July 1, 1892. Disponível em: <https://doi.org/10.5840/monist18922434>. Acesso em: 17 abr., 2019.

VAN DIJCK, J. Confiamos nos dados? As implicações da datificação para o monitoramento social. Revista Matrizes, São Paulo, Brasil, v. 11, n. 1, jan./abr., 2017. Disponível em: $<$ https://www.revistas.usp.br/matrizes/article/download/131620/127911>. Acesso em: 20 mar 2018. 